\title{
Study on the Quality Evaluation System of College Information Network
}

\author{
Zhengyong Liu \\ Network Information Center \\ Nanjing University of Science and Technology \\ Nanjing 210094, China \\ Tel: 86-25-8431-5651 E-mail: zyliu@mail.njust.edu.cn
}

\begin{abstract}
At present, various colleges have established their own information networks. Aiming at actual demand to different colleges, the quality evaluation system of information network is urgent problem which should be solved. In this article, we will study the quality evaluation system of college information network from three aspects including the evaluation of the hardware system, the evaluation of the management system and the evaluation of the application system of the college information network.
\end{abstract}

Keywords: Information network, Research, Quality evaluation, Evaluation system

\section{Introduction}

With the quick development of computer network, domestic colleges establish the campus information network in succession, and the information networks of most colleges are continually reconstructed and gradually updated, and the campus information network has been the basic condition for teaching, scientific research and management. From network technology, network application and network management, the campus information network is the large-sized computer network with the highest network technical content, the most complete network application requirement and the most complex network management. The users facing the campus information network mainly include college teachers and students, so very high requirements are required for the campus information network whether from network technology, network application or network management, but many problems still exist in the campus information network, so it has not better fulfill college teachers and students' works and studies, and the campus information network needs to be optimized, updated and reconstructed. At present, the capital amount is the only factor to decide the layout and the construction when the campus information network is optimized, updated and reconstructed, so scientific theoretic base is deficient, and the layout is blind. For the campus information network, the hardware system is base, the management system is guarantee, and the application system is the attention. So to study the college information network is to study these three systems and the interior association among these three systems.

In this article, we will study the quality evaluation system of college information network from three aspects including the evaluation of the hardware system, the evaluation of the management system and the evaluation of the application system.

\section{Quality evaluation of hardware system}

When designing a campus information network, the hardware system should be first considered, and when evaluating a campus information network, the hardware system is the first factor. So we need analyze and study the hardware system to design and evaluate the campus information network.

\subsection{Network system structure analysis}

Figure 1 is the poetic campus information network principle sketch, and we analyze the sketch as follows.

The main composing of the network system structure is the topology structure connecting the network equipment, and the network technology adopted by the campus information network is the Ethernet technology. According to the size of college, the campus information trunk network can be divided into Ethernet of ten thousand-mega and kilomega Ethernet. The campus information network mostly adopts the three-tiers structure mode including the core tier, the cluster tier and the access tier, and the core tier is composed by one set or several sets of exchanger and these exchangers are connected by ten thousand-mega Ethernet and kilomega Ethernet, and the core tier and the cluster tier are connected by ten thousand-mega Ethernet and kilomega Ethernet, and the cluster tier and the access tier are connected by kilomega Ethernet and hundred-mega Ethernet, and the computer terminal access is accessed by 
hundred-mega, and according to the terminal quantity and application of computer to confirm whether the campus information trunk network is connected by kilomega or ten thousand-mega, and the router, firewall, IDS, load equilibrium and other network equipments can be updated and increased at any time according to the demand of application and management.

\subsection{Server system structure analysis}

The server system is the base of network service, and the performance of server should fulfill the service offered by network, and the system structure of server directly decides the quality of service offered by network, and the structure design of network server system can adopt the "three tiers/ multiple tiers computation" frame based on the Internet application service mode, and the three tiers model is seen in Figure 2. The functions of various tiers are described as follows.

(1) Client tier. It is the emitting station for user access and user request, and the typical application is the network browser.

(2) Server tier. The typical applications include the Web server and the application server to run operation code and logic.

(3) Data tier. The typical applications include relationship database and other back-end data resources such as Oracle database.

\subsection{Analysis of network system exit design}

At present, various college information networks are directly connected with CERNET by kilinega or hundred-mega, and most colleges possess second exit or third exit which respectively connected with Telecom or other nets. When one college information network has several exits, the key to design the exit of network system is to fully utilize the exit bandwidth and enhance the speed that college network users interview exterior nets to the maximum extents. We will analyze and study the design of network system exit from two aspects including the route technology and the bandwidth management.

\section{(1) Route technology}

The route technology can be divided into static route selection and dynamic route selection, and different route selections needs the supports of different hardware systems, so when we design the network system exit, we should first confirm whether the exit route is to select static route or dynamic route.

The selection of static route is to control the interview of different exits to different exterior nets, and the selection of dynamic route is the optimal route selection.

(2) Bandwidth management

The bandwidth management is to manage the network exit bandwidth occupied by college interior users when they interview the exterior net resource. From Figure 1, the bandwidth manager is the hardware equipment, and it is set in front of the route management equipment, and it is to manage the campus net exit width occupied by corresponding IP to users with different characters in the interior of the campus net.

\section{Analysis of application system quality evaluation}

The intention to construct campus information network is the application, and some basic applications such as WWW, FTP, BBS, E-mail and VOD of present college information network are mature, and what we should emphasize is the construction of college digital campus, i.e. we should establish an advanced digital campus from following aspects.

\subsection{Software frame system}

The application system frame design of college digital campus is mainly the total frame system of public database platform in the whole digital campus, and it is seen in Figure 3. It is composed by the operation tier, the display tier, the resource tier and the system tier, and its core is the operation tier.

(1) Operation tier

The operation tier is the core support tier to operate the public database platform, and it is composed by the operation objective tier, the public service tier and the communication gateway.

(2) Display tier

The main function of the display tier is to interview various application system function offered by the application service tier, and display the result returned by application logic to users through various technical means, and make uses could access the management information system platform through different interfaces and communication modes.

(3) Resource tier

The system resource tier could offer basic services for the running of the application service tier, and it includes the 
database system which can offer the storages of basic data and running data.

(4) Other system tier

For some existing operation systems, we should keep them or integrate them through EAI Server. We could adopt three cluster modes including data cluster, operation cluster and view cluster.

\subsection{Performance requirements}

(1) Running performance

For common colleges, there are many users, so the network should achieve that the network could support twenty thousand users, and the page interview speed could achieve three seconds/ 500 hundred people, and the maximum delay could not exceed 30 seconds, and the system can ensure the running of $7 * 24$ hours, and the system could support load equilibrium and extension.

(2) Education operation and teaching standard

The system could support the management information system construction standard of the Education Ministry of China, the SCORM standard, IMS standard, DLTS, IEEE LTSC, international current network agreement and route agreement and other opening agreement standards.

\subsection{Door platform}

(1) Single sign on (SSO)

The requirement that users log on the digital campus application platform through the door is that the system platform could complete users' single sign on when entering into another function application from one function according to users' role and limitation.

(2) Interview control based on strategy

The system could safely implement remote interview, and authorize that users only need one Web browser based on Java technology and one connection which could log on the internet at any time to see their individual desk contents. Once users could $\log$ on and pass the authentication, they could safely implement remote interview bag including the encrypted private interview to the data document on any interior document server.

(3) Limitation management

The system design could offer flexible limitation setups according to the authorizations of role, role + organization, user, or organization, and the individual information must be highly secreted and only individual could inquire. According to the fixed mode, the back-stage management must strictly implement limitation control by managers, and the system information implements strictly limitation control according to the organization (college, department, specialty and class).

\subsection{Selection of database}

The database is the core part to establish the digital campus and teaching management system. Generally speaking, the database system of college digital campus has complex data type, huge data amount, the coherence of the data and high reliability, so the selection of database is the important content in the construction of the whole system. For the selection of database, we should consider the requirements including the mature product with maximum market share, the design based on B/S system structure, supporting SQL standard, supporting parallel technology and dual computer copy, supporting multiple CPU and multiple Cluster structures, offering database type and log image, continually completing data encrypt on media, supporting real time copy and stretch copy granularity and disaster recover, transparent and DDB technology, multithreading and multi-course technology and supporting various application development tools.

\section{Quality evaluation analysis of management system}

The college information network management system includes network equipment management, application management, security management and user management.

\subsection{Network equipment management}

As seen in Figure 1, the hardware system is the base in the college information network, and the hardware system includes not only good network equipment and scientific and reasonable network structure, but scientific and effective management to these network equipments, for example, the topology structure of the whole network and the flux analysis in the network, and the key of network equipment management is to deploy special management system aiming at various equipments in the information network, and offer perfect technical management means for network managers.

\subsection{Application management}

The intention of college information network construction is the application, and with the development of network 
technology, the applications of network are more and more complex, which needs us implement scientific classification and management to the network applications. We should differentiate which network information is especially for interior users, which network information is aiming at students, which network information is aiming at teachers and which network information is completely open. Only good classification to these network information and effective management to these network applications can fully ensure and utilize the application of the whole information network.

\subsection{Security management}

The network security is more and more emphasized in the college information network, and the network security management mainly includes two aspects such as anti-invasion and antivirus.

The anti-invasion is to prevent illegal operations and attacks from the interior and exterior of college information network. The antivirus is to prevent the spread of various network viruses from the interior and exterior of college information network, and eliminate existing viruses at the same time.

\subsection{User management}

The user management in college information network is mainly to manage interior users. To standardize the network behaviors of interior users, there are two means including technology and regulation to manage users.

The technical means is to manage the system through the access terminal authorization system and the exit user application. And the regulation is to mainly standardize network users' network behaviors through administration means.

\section{Comprehensive evaluation}

It is difficult to comprehensively evaluate one college information network, because there is not one fixed mode for the evaluation to different information networks, and the size, application and hardware support platform of different college information networks are different, so aiming at different college information networks, we can follow several principles.

\subsection{Application}

Because the intention to establish the college information network is the application, so when we evaluate the application of college information network, we should judge whether the application offered by the information network can fulfill the actual application of the whole college, and whether the application is stable, and whether there are corresponding technical application development and support.

\subsection{Hardware}

All applications of college information network needs the support of hardware platform, and when we evaluate the hardware system of college information network, we should judge whether the whole hardware support platform could fulfill the demand of application, and implement technical evaluation to the stability of the hardware system.

\subsection{Management}

The management is very important for the work of college information network. When we evaluate the management system of the college information system, we should do the works from two aspects. One is the technical means, i.e. whether we can implement good management to the hardware system, application system and network users technically. The second is whether we can standardize users' net behaviors from the system.

\section{Conclusions}

The comprehensive evaluation of college information network is a very huge and complex system. We should implement comprehensive evaluation for the college information network from three aspects including application system, hardware system and management system. For different colleges, if the college information system could fulfill the whole demand of college information network and possess higher stability, so it is the information network with high quality.

\section{References}

Bai, Yingcai \& Guan, Haibing. (2000). Design and Application of Computer Network Management System. Beijing: Tsinghua University Press. P.38-55.

Chai, Chenyang. (2002). Research and Implementation of a Network Charging System Based on Campus Network. Computer Engineering and Science. No.24(5). P.51-52.

Linchuang, Shan, Zhiguang \& Ren, Fengyuan. (2004). Service Quality of Computer Network. Beijing: Tsinghua University Press.

Tanenbaum, interpreted by Pan, Aimin. (2004). Network bass (4th edition). Beijing: Tsinghua University Press. 
Tanenbaum, interpreted by Xiong, Guixi. (2004). Computer Networks (3rd edition). Beijing: Tsinghua University Press. P.487-496.

Xu, Zhiwei, Feng, Baiming \& Liwei. (2004). Network Computing Technology. Beijing: Publishing House of Electronics Industry.

Yu, Hongzhi. (2002). Multiple Tier Management Frame to Establish University Campus Network. Journal of Southeast University. No.11. P.140-142.

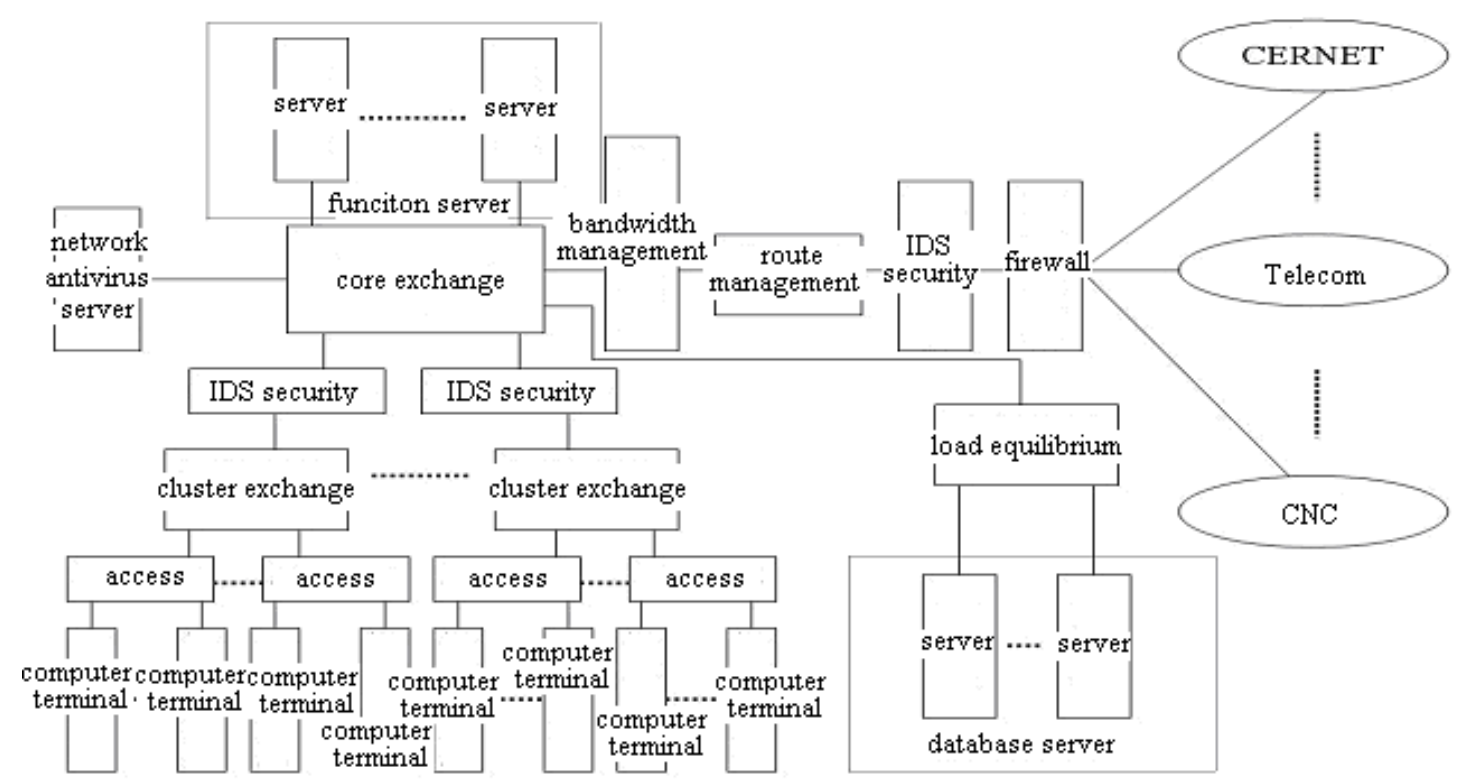

Figure 1. College Information Network Principle

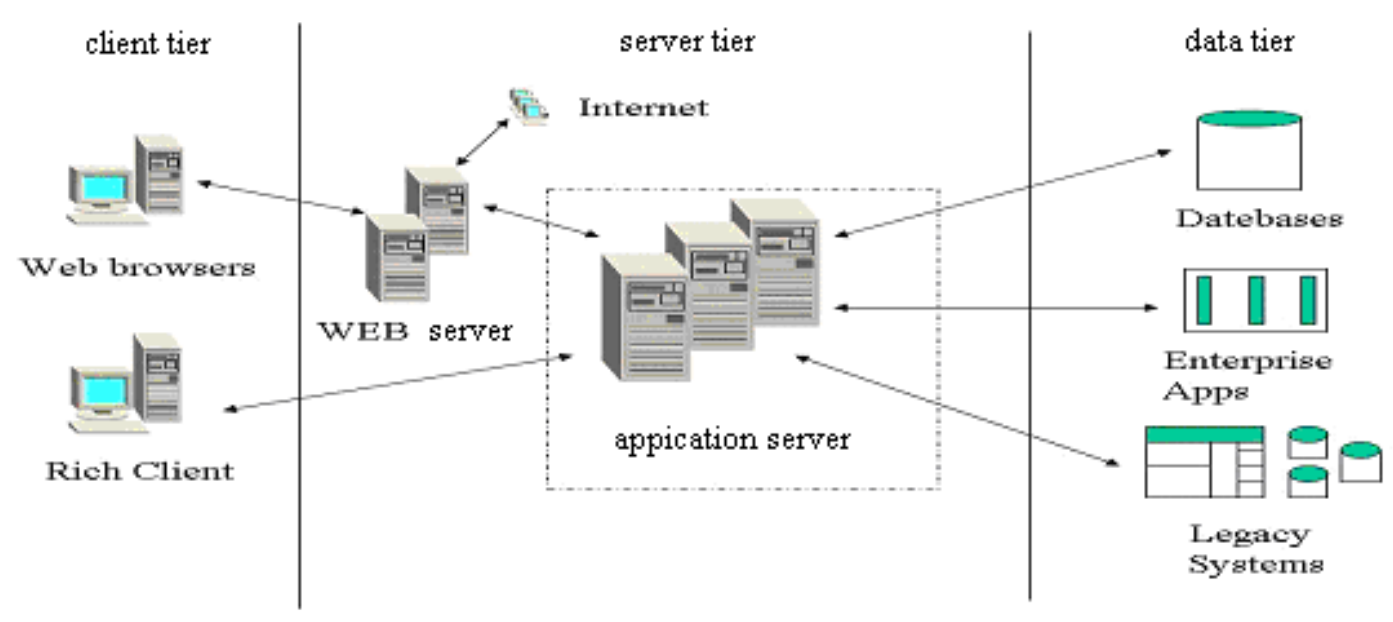

Figure 2. Server System Structure 


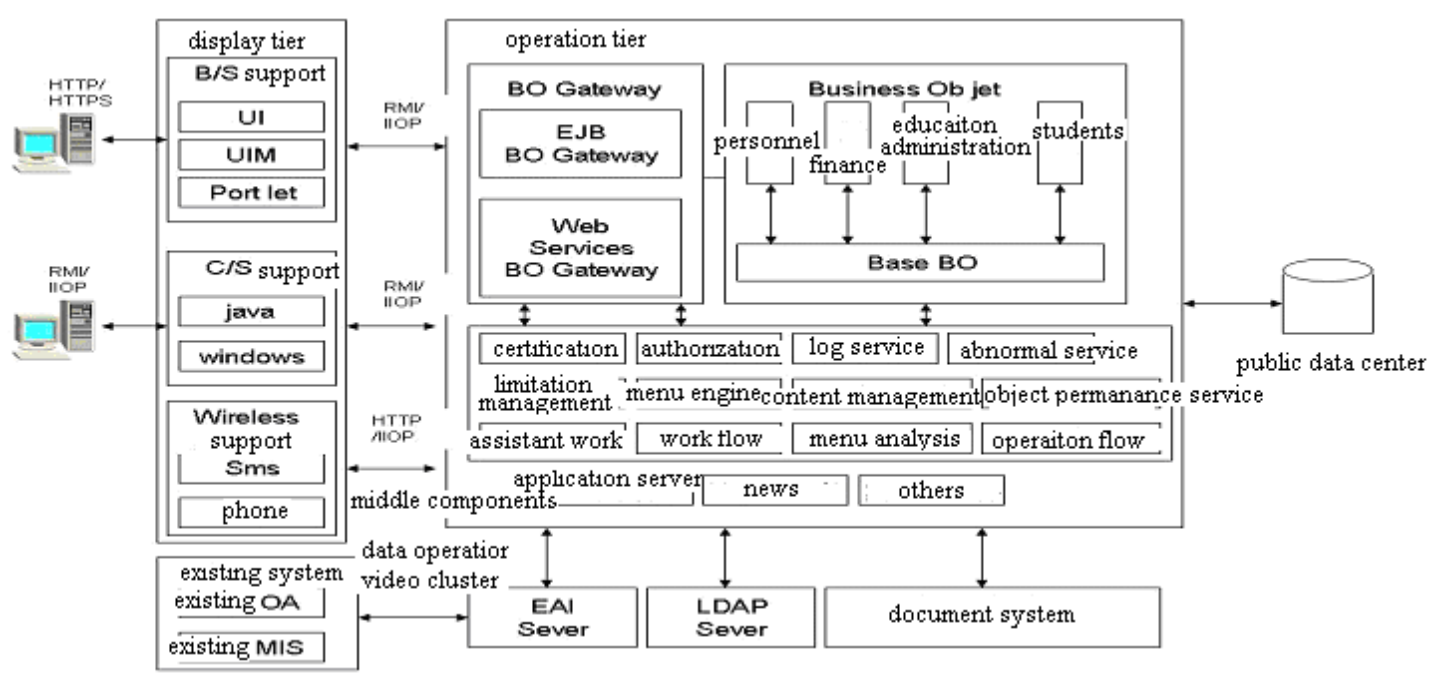

Figure 3. Structure Principle of Software System Frame 